\title{
Ectopic pregnancy concomitant with borderline ovarian tumor
}

\author{
Ana Carolinne da Silva ${ }^{1}$, Isac Souza Silva Rodrigues ${ }^{1}$, Antônio Carlos Oliveira de Meneses ${ }^{2}$, Eddie \\ Fernando Candido Murta ${ }^{1}$, Rosekeila Simões Nomelini ${ }^{1}$ \\ ${ }^{1}$ Research Institute of Oncology (IPON)/Department of Gynecology and Obstetrics, Federal University of Triângulo Mineiro, \\ Avenida Getúlio Guaritá, 214. Bairro Abadia. 38025-440. Uberaba-MG Brazil \\ ${ }^{2}$ Service of Surgical Pathology, Federal University of Triângulo Mineiro, Avenida Getúlio Guaritá, 214. \\ Bairro Abadia. 38025-440. Uberaba-MG Brazil
}

\begin{abstract}
Summary
The most common clinical presentation of ectopic pregnancy is vaginal bleeding in the first trimester and abdominal pain. The existence of a borderline tumor concomitant to ectopic pregnancy has not been described in the literature. The study reported a patient with ectopic pregnancy undergoing surgical treatment, and during the procedure was found an ovarian cyst. Histopathology confirmed the diagnosis of borderline serous cystadenoma. The article demonstrates the need for anatomic-pathological investigation of ovarian cysts, and especially the surgical care in the approach of ectopic pregnancy concomitant with these cysts, since it can occur in women who still desire children, aiming at the maintenance of fertility.
\end{abstract}

Key words: Ectopic pregnancy; Borderline serous cystadenoma; Surgical procedure; Ovarian neoplasms.

\section{Introduction}

Borderline ovarian tumors exhibit pathological features that incorporate aspects of benign and malignant tumors. Subtypes of borderline ovarian tumors comprise distinct biological, pathogenic and molecular entities, preventing experts from establishing a single system for classifying borderline ovarian tumors. Here we report on a patient with ectopic pregnancy concomitant with borderline serous cystadenoma. To our knowledge, this is the first such case to be described in the literature.

\section{Case Report}

A 20-year-old woman (gravida 1, para 1) presented to the Obstetrics and Gynecology Service of the Federal University of Triângulo Mineiro with abdominal pain and transvaginal bleeding. Her pulse and blood pressure were normal. Her hypogastrium was painful. Bimanual vaginal touch was painless, with a small amount of bleeding.

Transvaginal ultrasonography showed normal uterus, with an endometrium thickness of $0.48 \mathrm{~cm}$, a normal right ovary, and a left ovary with a cystic formation of slightly thickened walls and anechoic content, measuring $8.3 \times 6.4$ $\times 7.3 \mathrm{~cm}$. Doppler imaging revealed a resistance index of 0.59 . The pelvis contained $500-750 \mathrm{ml}$ of fluid, which extended to parietocolic recesses. Beta-HCG was positive, and the blood hemoglobin was $10.4 \mathrm{mg} / \mathrm{dl}$.

During the laparotomy, an ectopic pregnancy was found in the left fallopian tube in association with a left ovarian cyst. The ectopic pregnancy extended throughout the uterine tube. The ovarian cyst measured about $9 \mathrm{~cm}$ in diame- ter, with no ovarian parenchyma. Therefore a left salpingooophorectomy was performed.

Microscopic analysis of the placenta revealed chorionic villi characteristic of the first trimester of gestation with myxoid stroma, without blood vessels, presenting a double layer of trophoblasts (syncytium and cytotrophoblasts), with polar proliferation of the trophoblasts. The ovary presented micropapillary proliferation, with small nuclei and scarce cytoplasm, as well as continuity with stromal fibrous connective tissue (hobnail nuclei) (Figure 1). The histopathological diagnosis was reported to be tubal ectopic pregnancy and serous cystadenoma of the left ovary with a focus of borderline serous tumor. Histopatological examination also indicated a hematoma within the tubal lumen, necrosis of the chorionic villi and absence of fetal tissues. The patient was followed up at the Gynecological Oncology Clinic by interdisciplinary team with trimestral tumor markers (CA-125, CA 19.9, and CA15.3) and semester abdominal and transvaginal ultrasonography.

\section{Discussion}

Ectopic pregnancy is characterized by the implantation and development of an embryo outside the uterine cavity [2]. It is a common cause of acute pelvic pain [3]. Although the etiology remains unknown, hypotheses include poor functionality of the uterine tubes or inflammatory processes of the tunica albuginea [4].

Ectopic pregnancy is an important cause of mortality and morbidity in women. Early treatment may be performed with surgery or methotrexate [5]. The success rate of methotrexate ranges from $63 \%$ to $96.7 \%$, being an alter-
Eur. J. Gynaecol. Oncol. - ISSN: 0392-2936 XLI, n. 5, 2020

doi: $10.31083 /$ j.ejgo.2020.05.5328
This is an open access article under the CC BY 4.0 license (https://creativecommons.org/licenses/by/4.0/). 


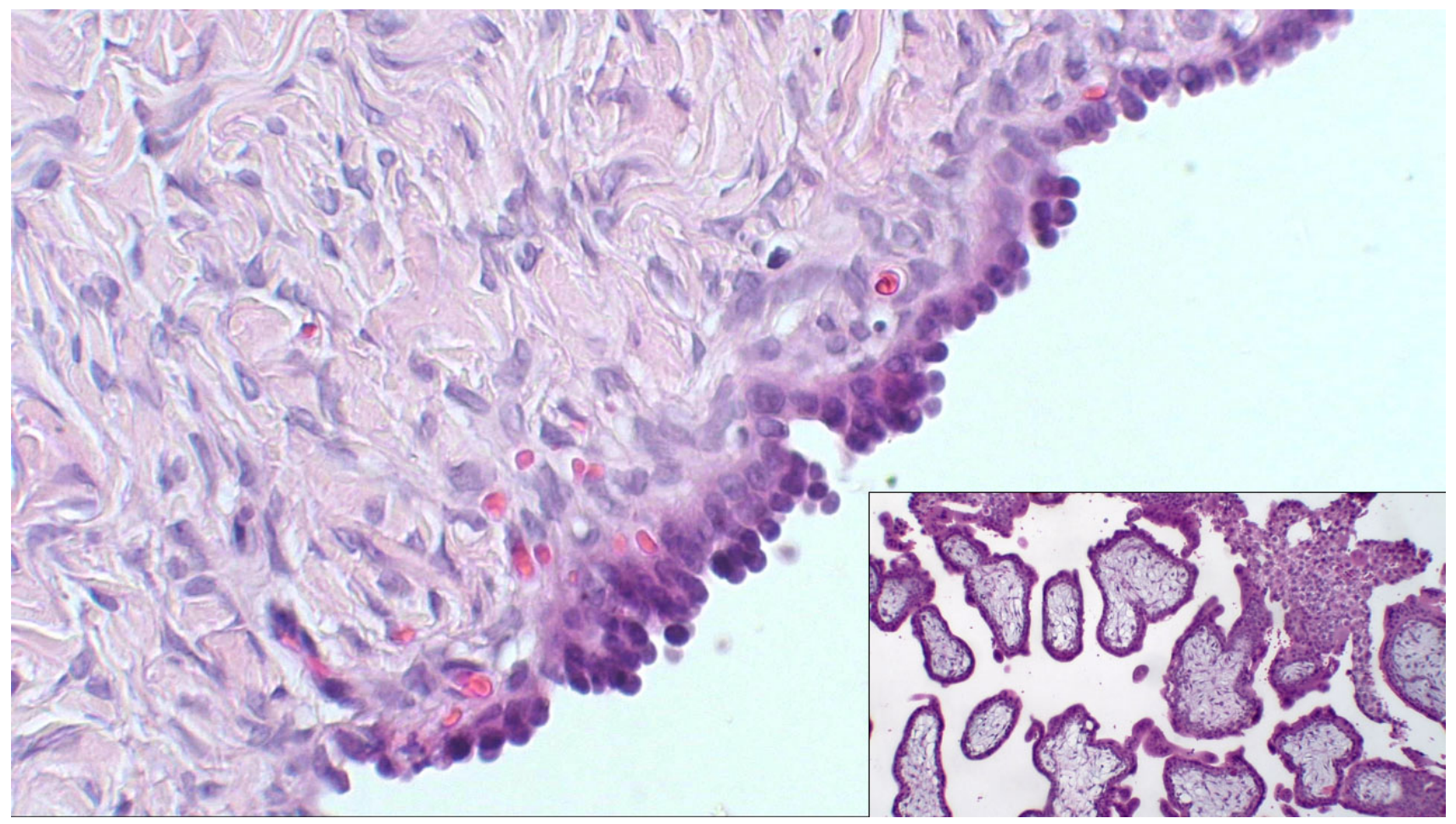

Figure 1. - Epithelium with micropapillary proliferation, with small nuclei and scarce cytoplams, continuity with stromal fibrous connective tissue (hobnail nuclei) $(400 \times)$. Insert: Placenta with chorionic villi of the first trimester of gestation with myxoidstroma, without blood vessels, presenting a double layer of trophoblast $(400 \times)$.

native for hemodynamically stable patients and low betaHCG (1500 to $5000 \mathrm{IU})$ [6]. Clinical treatment is an option when the patient wants new pregnancies. The use of methotrexate is safe and does not influence ovarian reserve or the rate of live births following in vitro fertilization [7]. In our case, the patient did not present criteria for clinical treatment, because she presented symptoms and signs of a ruptured ectopic pregnancy.

Borderline ovarian tumors are characterized by nuclear abnormalities and increased mitotic activity, without infiltrative growth or stromal invasion. They represent about 10 to $20 \%$ of ovarian epithelial tumors. One-third of patients are younger than 40 years. Therefore, preservation of fertility is imperative, and radical surgery is not advisable. Ovarian borderline tumors are most often limited to the ovaries. Most are diagnosed in Stage I (FIGO), and their spread to the pelvis and abdomen at the time of diagnosis is rare [8].

The treatment of borderline ovarian tumors is surgical, with complete resection of the tumor. In postmenopausal women, treatment includes peritoneal washing, bilateral salpingo-oophorectomy, multiple peritoneal biopsies, omentectomy, and the resection of macroscopically visible metastases. It is not necessary to perform lymphadenectomy and/or hysterectomy in all patients. If the woman desires to preserve fertility, a unilateral salpingooophorectomy may be performed. In those cases the uninvolved ovary should be carefully evaluated, but biopsy is not necessary because it impairs ovarian reserve and causes adhesions [9]. In this case, there was an initial suspicion of ectopic pregnancy. However, during surgery, a cyst in the left ovary was found. A unilateral salpingo-oophorectomy was performed. The surgery was not extended after confirmation of the borderline tumor diagnosis because the patient desired to become pregnant again. Follow-up was performed at the Gynecologic Oncology Clinic with clinical examination, tumor markers and imaging tests every six months. We reinforce the need for multidisciplinary followup by the surgeon, oncologist, gynecologist and obstetrician of the adnexal masses, especially after the confirmed diagnosis of borderline tumor, since this may behave benign or rarely malignant in the follow-up.

\section{Conclusions}

Ovarian neoplasm may be an incidental finding at pelvic surgery in young women. Therefore, this case suggests the importance of clinical and ultrasonographic follow-up of patients undergoing clinical treatment for ectopic pregnancy, because ultrasonography may not differentiate an adnexal mass restricted to the tube from one restricted to the ovary. After clinical treatment, the patient must be followed until disappearance of the adnexal mass. This may prevent an ovarian tumor from going undiagnosed after the treatment of ectopic pregnancy. 


\section{Ethics approval and consent to participate}

Consent was obtained from the patient for publication of this case report. The study was approved by the Research Ethics Committee of the Federal University of the Triângulo Mineiro (protocol number 62195816.3.0000.5154).

\section{Author contributions}

Ana Carolinne da Silva: data collection; writing. Isac Souza Silva Rodrigues: data collection; writing. Antônio Carlos Oliveira de Meneses: writing; revision. Eddie Fernando Candido Murta: revision; supervision. Rosekeila Simões Nomelini: conceptualization; writing; revision; supervision.

\section{Funding sources}

CNPq (Conselho Nacional de Desenvolvimento Científico e Tecnológico), FUNEPU (Fundação de Ensino e Pesquisa de Uberaba), FAPEMIG (Fundação de Amparo à Pesquisa do Estado de Minas Gerais), and CAPES (Coordenação de Aperfeiçoamento de Pessoal de Nível Superior - Brasil).

\section{Acknowledgements}

The authors wish to acknowledge the funding received from the CNPq (Conselho Nacional de Desenvolvimento Científico e Tecnológico), FUNEPU (Fundação de Ensino e Pesquisa de Uberaba), FAPEMIG (Fundação de Amparo à Pesquisa do Estado de Minas Gerais), and CAPES (Coordenação de Aperfeiçoamento de Pessoal de Nível Superior - Brasil).

\section{Conflict of Interest}

The authors declare no conflicts of interest.
Submitted: August 01, 2019

Accepted: October 28, 2019

Published: October 15, 2020

\section{References}

[1] Hauptmann S., Friedrich K., Redline R., Avril S.: "Ovarian borderline tumors in the 2014 WHO classification: evolving concepts and diagnostic criteria". Virchows Arch., 2017, 470, 125-142.

[2] Jurkovic D., Wilkinson H.: "Diagnosis and management of ectopic pregnancy”. BMJ, 2011, 342, d3397-d3397.

[3] Pages-Bouic E., Millet I., Curros-Doyon F., Faget C., Fontaine M., Taourel P.: "Acute pelvic pain in females in septic and aseptic contexts”. Diagn. Interv. Imaging, 2015, 96, 985-995.

[4] Panda S., Darlong L., Singh S., Borah T.: "Case report of a primary ovarian pregnancy in a primigravida". J. Hum. Reprod. Sci., 2009, $2,90$.

[5] Mergenthal M.C., Senapati S., Zee J., Allen-Taylor L., Whittaker P.G., Takacs P., Sammel M.D., Barnhart K.T.: "Medical Management of Ectopic Pregnancy with Single-Dose and Two-Dose Methotrexate Protocols: Human Chorionic Gonadotropin Trends and Patient Outcomes". Am. J. Obstet. Gynecol., 2016, 215, 590.

[6] Ohannessian A., Crochet P., Courbiere B., Gnisci A., Agostini A.: "Methotrexate treatment for ectopic pregnancy after assisted reproductive technology: A case-control study". Gynecol. Obstet. Fertil., 2016, 44, 341-344

[7] Boots C.E., Hill M.J., Feinberg E.C., Lathi R.B., Fowler S.A., Jungheim E.S.: "Methotrexate does not affect ovarian reserve or subsequent assisted reproductive technology outcomes". J. Assist. Reprod. Genet., 2016, 33, 647-656.

[8] du Bois A., Trillsch F., Mahner S., Heitz F., Harter P.: "Management of borderline ovarian tumors". Ann. Oncol., 2016, 27, i20-i22.

[9] Mangili G., Somigliana E., Giorgione V., Martinelli F., Filippi F., Petrella M.C., et al.: "Fertility preservation in women with borderline ovarian tumours". Cancer Treat. Rev., 2016, 49, 13-24.

Corresponding Author: ROSEKEILA SIMÕES NOMELINI, Ph.D.

Research Institute of Oncology (IPON)/Discipline of Gynecology and Obstetrics,

UFTM, Av. Getúlio Guaritá, 330, Bairro Abadia, 38025-

440 Uberaba-MG (Brazil).

e-mail: rosekeila@terra.com.br;

rosekeila.nomelini@pq.cnpq.br 